\title{
PERENCANAAN JADUAL INDUK PRODUKSI DENGAN MENGGUNAKAN METODE DISAGREGAT GUNA MEMENUHI PERMINTAAN YANG BERFLUKTUASI
}

\author{
Eti Kristinawati ${ }^{1}$
}

\section{ABSTRACT}

Every company always tries to serve all customer's demand. This need a good planning and schedulling to keep flow production. PT Binarenata is one company which produce many kind of metal products. Currently, this company has problem in material handling of product and lack of another product.

To solve this problem, this company made Master Production Schedule using disagregat method to due the fluctuation demand. From analysis data can be found the number of worker with minimum cost in the next production planning is about 966 persons with cost about Rp 49.431.714.000,00. Implementing this Master Production Schedule can reduce production cost about Rp5.829.363.807,00 or $76,3 \%$.

Key Words : Master Production Schedule, Disagregat, Fluctuation.

\section{PENDAHULUAN}

Suatu perusahaan yang bergerak dalam bidang jasa maupun manufaktur akan selalu berusaha untuk mencapai target perusahaan berupa laba yang maksimal dengan biaya atau pengeluaran paling minimum. Dalam mencapai target perusahaan tersebut tidak lepas dari pentingnya menerapkan fungsifungsi manajemen yaitu perencanaan, pengorganisasian, pengarahan dan pengawasan. Karena setiap perusahaan pasti menginginkan agar produksi yang dihasilkan dapat memenuhi permintaan konsumen. Untuk itu diperlukan suatu perencanaan yang matang dalam memenuhi permintaan tersebut. Salah satu fungsi perencanaan yang penting adalah perencanaan dan penjadualan produksi, karena dengan perencanaan dan penjadualan produksi yang baik akan mempengaruhi pada kelancaran proses produksi itu sendiri.

PT. Binarenata Perdana adalah sebuah perusahaan yang memproduksi berbagai jenis produk yang terbuat dari logam, bukan hal yang tidak mungkin akan terjadi kelebihan ataupun kekurangan produk akibat tidak adanya perencanaan yang baik, sehingga seringkali permintaan konsumen tidak dapat dipenuhi. Sekarang ini perusahaan dihadapkan dengan masalah penumpukan suatu jenis produk dan sebaliknya kekurangan produk lain pada suatu saat. Karena selama ini PT Binarenata Perdana melaksanakan penjadualan produksi berdasarkan pengalaman dan perkiraan penjualan periode sebelumnya. Untuk mengatasi masalah tersebut, perusahaan perlu menetapkan Jadual Induk Produksi yang baik sehingga dapat diketahui kapan 
dan berapa banyak masing-masing produk harus diproduksi dan akhirnya dapat memenuhi permintaan konsumen dengan tepat waktu dan jumlah yang sesuai.

\section{TINJAUAN PUSTAKA}

\section{Peramalan permintaan}

Menurut T. Hani Handoko

"Peramalan merupakan suatu usaha untuk meramalkan keadaan dimasa mendatang melalui pengujian keadaan dimasa lalu."

Dalam sistem produksi periode perencanaan diklasifikasi sebagai berikut :
a. Jangka pendek $(<1$ tahun $)$
b. Jangka menengah (1 sampai 5 tahun )
c. Jangka panjang ( $>5$ tahun )

Klasifikasi model peramalan Model

Kualitatif

\section{Model Kuantitatif}

a. Time Series / kurun waktu

* Model Trend Linier

Model Trend non Linier

- Trend Eksponensial

- Trend Parabola

* Model Moving average

* Model

Eksponensial

Smoothing Tunggal

* Model

Eksponensial

Smoothing Ganda

b. Kausal

* Ekonometrik

* Regresi Multivariete

\section{Model Kualitatif}

a. Delphi

b. Subyektif Estimasi Survey

\section{Model Trend Linier}

$$
y^{\prime}=a+b x
$$

Dimana :

$Y^{\prime}=$ besarnya nilai peramalan

$\mathrm{a}=$ nilai trend pada periode dasar

$\mathrm{b}=$ tingkat perkembangan nilai yang diramal

$\mathrm{X}=$ unit periode yang di hitung dari periode dasar

Untuk memperoleh besarnya nilai $a$ dan $b$ digunakan metode titik tengah dimana, a dan b diformulasikan sebagai berikut :

$$
\begin{aligned}
& a=\frac{\sum y}{n} \\
& b=\frac{\sum x y}{\sum x^{2}}
\end{aligned}
$$

Dimana :

$$
\mathrm{n}=\text { banyaknya data }
$$

\section{Model Trend Ekponensial}

$$
y^{\prime}=a b^{x}
$$

Untuk mendapatkan nilai a dan b, maka diformulasikan sebagai berikut:

$$
\begin{aligned}
& \log a=\frac{\sum \log y}{n} \\
& \log b=\frac{\sum x \log y}{\sum(x)^{2}}
\end{aligned}
$$

\section{Menghitung standart Error of Estimasi}

$$
S E E=\sqrt{\frac{\sum\left(y-y^{\prime}\right)^{2}}{n-2}}
$$


Dimana :

$\mathrm{Y}=$ data historis permintaan pada periode $t(t=1,2,3 \ldots)$

$Y^{\prime}=$ besarnya niali peramalan periode $k e t(t=1,2,3 \ldots)$

\section{Memilih model peramalan yang terbaik}

Memilih model peramalan yang relevan adalah yang memiliki Standart Error of Estimasi (SEE) terkecil.

\section{Hipotesa (F test)}

Adapun formulasi dari $\mathrm{F}$ test ini adalah :

Asumsi : $\mathrm{Ho}=\mathrm{SEE} 1<\mathrm{SEE} 2$

$$
\mathrm{Ha}=\mathrm{SEE} 1>\mathrm{SEE} 2
$$

Fhitung $=\frac{(S E E 1)^{2}}{(S E E 2)^{2}}$

\section{Dimana:}

SEE1 $=$ Standart Error of Estimasi model ke 1

SEE2 $=$ Standart Error of Estimasi model ke 2

Sedangkan untuk menguji hipotesa (H0) digunakan :

$$
\mathrm{F} \text { tabel }=\mathrm{F} \alpha(\mathrm{V} 1, \mathrm{~V} 2)
$$

Dimana :

$$
\begin{aligned}
& \alpha=\text { Taraf signifikasi } \\
& \mathrm{Vl}=\text { Derajat kebebasan pembilang } \\
& \quad(\mathrm{dk}=\mathrm{n}-1)
\end{aligned}
$$

$\mathrm{V} 2=$ Derajat kebebasan penyebut $(\mathrm{dk}=\mathrm{n}-2)$

Kriteria dari Ftest adalah: Tolak hipotesa jika F hitung $>$ F tabel

Setelah didapat model yang terbaik, hasil peramalan yang didapat disesuaikan dengan prosentase cacat produk untuk masing masing jenis produk.

\section{Menyesuaikan Hasil Peramalan dengan}

Prosentase Cacat Yang Ada Untuk Masing- masing Item.

$$
p g_{i j}=\frac{p o i j_{t}}{1-p i j}
$$

Dimana :

$$
\begin{aligned}
& \text { Pgij }_{,_{t}}=\text { jumlahyanharusdiproduksi } \\
& \text { Poij }_{,_{t}}=\text { Ramalanper min taan } \\
& P i j=\text { Nilaiprosenta } \mathrm{sec} \text { acat } .
\end{aligned}
$$

\section{Perencanaan Agregat}

Definisi perencanaan agregat menurut David D Bedwort dan James Bailey yaitu "Perencanaan dibuat untuk menentukan total permintaan dari seluruh elemen produksi dan jumlah tenaga kerja yang diperlukan."

Alternatif mendapatkan variasi tingkat produksi antara lain berupa :

Regular time

Over time

Inventory

* Subcontracting

* Backordering

Biaya-biaya yang terkait dengan alternatif produksi pada PT.Binarenata Perdana adalah:

* Biaya regular time

* Biaya Over Time

* Biaya Inventory

Ada berbagai macam metode perencanaan agregat. Klasifikasi metode tersebut dapat didasarkan pada hubungan 
biayanya dan pada optimal atau tidak optimal hasilnya. Dalam hal ini perencanaan agregat akan diuraikan secara konseptual melalui metode Transportasi.

Langkah-langkah penyelesaian masalah perencanaan agregat dengan metode transportasi menurut David D. Bethworth dan James E :

1. Definisikan jenis alternatif yang akan disertakan dalam kegiatan produksi beserta kapasitasnya. Alternatif produksi itu dapat berupa :

- Reguler Time (RTt)dengan kapasitas per periode $\mathrm{Lt}$

- Over Time (Ott)dengan kapasitas Mt

- Inventori (It)dengan kapasitas tidak terbatas
Pada metode transportasi ini tidak diperhitungkan alternatif subcontracting

2. Tentukan biaya per unit

- Biaya Regular Time (r)

- Biaya Over Time (v)

- Biaya Simpan (Ch)

3. Jumlahkan semua kapasitas yang tersedia selama satu horison termasuk inventori awal (jika ada) yaitu jika suatu horison terdapat $\mathrm{n}$ periode.

MakaTotalKapasitas $=\sum_{i=1}^{n}(I t+M t+I o)$

Jumlahkan total produksi selama periode yaitu:

$$
\text { TotalPer } \min \text { taan }=\sum_{t=1}^{n} Y t
$$

Dimana :

$\mathrm{Yt}=$ Permintaan pada periode $\mathrm{t}$

4. Persiapkan sebuah Matrik Transportasi seperti dibawah ini untuk memformulasikan masalah.

Tabel 1

Matrik Formulasi Masalah Agregat

\begin{tabular}{|c|c|c|c|c|c|c|}
\hline \multirow[t]{2}{*}{ Sumber } & \multicolumn{4}{|c|}{ Periode permintaan } & \multirow[t]{2}{*}{ Dummy } & \multirow{2}{*}{$\begin{array}{l}\text { Kapasitas } \\
\text { Produksi }\end{array}$} \\
\hline & 1 & 2 & 3 & 4 & & \\
\hline Io & 0 & $\mathrm{Ch}$ & $2 \mathrm{Ch}$ & $3 \mathrm{Ch}$ & 0 & Io \\
\hline RT1 & $\mathrm{r}$ & $\mathrm{r}+\mathrm{Ch}$ & $\mathrm{r}+2 \mathrm{Ch}$ & $\mathrm{R}+3 \mathrm{Ch}$ & 0 & Ll \\
\hline OT1 & $\mathrm{v}$ & $\mathrm{v}+\mathrm{Ch}$ & $\mathrm{v}+2 \mathrm{Ch}$ & $\mathrm{V}+3 \mathrm{Ch}$ & 0 & M1 \\
\hline RT2 & $\mathrm{r}+\mathrm{Cs}$ & $\mathrm{R}$ & $\mathrm{r}+\mathrm{Ch}$ & $\mathrm{R}+2 \mathrm{Ch}$ & 0 & $\mathrm{~L} 2$ \\
\hline Sumber & \multicolumn{4}{|c|}{ Periode permintaan } & Dummy & $\begin{array}{l}\text { Kapasitas } \\
\text { Produksi }\end{array}$ \\
\hline OT2 & $\mathrm{v}+\mathrm{Cs}$ & V & $\mathrm{v}+\mathrm{Ch}$ & $\mathrm{V}+2 \mathrm{Ch}$ & 0 & M2 \\
\hline RT3 & $\mathrm{r}+2 \mathrm{Cs}$ & $\mathrm{R}+\mathrm{Cs}$ & $\mathrm{r}$ & $\mathrm{r}+\mathrm{Ch}$ & 0 & L3 \\
\hline OT3 & $\mathrm{v}+2 \mathrm{Cs}$ & $\mathrm{V}+\mathrm{Cs}$ & $\mathrm{v}$ & $\mathrm{v}+\mathrm{Ch}$ & 0 & M3 \\
\hline RT4 & $\mathrm{r}+3 \mathrm{Cs}$ & $\mathrm{r}+2 \mathrm{Cs}$ & $\mathrm{r}+\mathrm{Cs}$ & $\mathrm{R}$ & 0 & L4 \\
\hline OT4 & $\mathrm{v}+3 \mathrm{Ch}$ & $\mathrm{v}+2 \mathrm{Ch}$ & $\mathrm{v}+\mathrm{Cs}$ & $\mathrm{V}$ & 0 & M4 \\
\hline Yt & Y1 & $\mathrm{Y} 2$ & Y3 & $\mathrm{Y} 4$ & & \\
\hline
\end{tabular}

5. Mengalokasikan permintaan tiap periode pada sel biaya terendah lebih dahulu. Bila semua permintaan sudah dialokasikan maka langkah terakhir adalah menjumlahkan total produksi tiap periode (baris 2,3,4,5) dan hasilnya menjadi rencana agregat untuk horison tersebut. 


\section{Perencanaan Disagregat}

Disagregat merupakan model untuk mendapatkan perencanaan produksi untuk tiap-tiap jenis produk, dalam tiap-tiap group produk berdasarkan rencana agregat. Seperti diketahui bahwa rencana agregat hanya memberikan rencana produksi untuk keseluruhan produk (dikelompokkan secara homogen). Oleh karena itu rencana agregat ini harus didisagregatkan kedalam jumlah produk untuk masing-masing jenis produk (item produk).

Prosedur untuk menyelesaikan masalah disagregat menurut David D Bethworth dan James E, ada dua langkah utama yaitu:

Memilih group mana yang akan diproduksi pada suatu periode. Untuk lebih jelasnya dinyatakan sebagai berikut :

$I_{i j, t-1}-D_{i j, t}<S_{i j, t}$

Dimana :

$$
I_{i j, t-1}=\text { Persediaan akhir untuk }
$$
produk $\mathrm{j}$ dalam group i pada periode $\mathrm{t}-1$ $D_{i j, t}=$ Permintaan produk $\mathrm{j}$ dalam group i pada periode $\mathrm{t}$

$$
S_{i j, t}=\text { Safety stock untuk produk } \mathrm{j}
$$

dalam group i pada periode $t$

Menentukan berapa banyak tiap-tiap produk dalam group produk yang telah diputuskan untuk diproduksi.

$$
N_{i}=\sqrt{\frac{I \sum\left(C_{i j} x T_{i j}\right)}{2 S_{i}}}
$$

\section{Dimana :}

$\mathrm{Ni}=$ Berapa kali ij diproduksi

$\mathrm{Cij}=$ Total biaya per unit untuk produk $\mathrm{j}$ dalam group $\mathrm{i}$

Tij $=$ Total permintaan produk $\mathrm{j}$ dalam group i selama 1 horison

$\mathrm{Si}=$ Set up cost untuk group I

$\mathrm{I}=$ Biaya inventory untuk produk $\mathrm{j}$ dalam group I

Sehingga kebutuhan produksi setiap kali produksi yang diharapkan sebesar :

$$
Q_{i j}=\frac{T_{i j}}{N_{i}}
$$

Namun $Q_{i j}$ tersebut belum menjadi keputusan produksinya tapi harus dilihat terlebih dahulu posisinya terhadap permintaan dan persediaan sekarang, serta disesuaikan dengan rencana agregat. Pertama harus dihitung perkiraan produk $\mathrm{j}$, group i tersebut, apakah melebihi permintaan atau persediaan pengamannya masing-masing $\left(r_{i j, t}\right)$

$r_{i j, t}=I_{i j, t-1}-D_{i j, t}-S_{i j, t}$

Kemudian dihitung jumlah produk yang akan diproduksi(Qij)

$$
\text { Qtotal }=\sum_{\text {semuagdalmz }} Q_{i j, t} K_{i j}
$$

Dimana :

$$
K_{i j}=\text { faktorkovers } i
$$

Q total menunjukkan total produksi dalam periode $t$. Jadi setelah dilakukan perhitungan hasilnya harus disesuaikan dengan rencana agregatnya. Factor penyesuaian untuk itu 
adalah $\frac{A t}{\text { Qtotal }}$ dengan At adalah rencana agregat untuk periode $t$. Jadi penyesuaian tiap-tiap Qij,t adalah :

$$
Q_{i j, t}(\text { adj })=Q_{i j, t}(\text { At } / \text { Qtotal })
$$

\section{Dimana}

At $=$ rencana agregat untuk eriode $\mathrm{t}$

$Q_{i j, t(a d j)}$ akan menjadi jadual induk produksi (JIP) untuk periode $t$

Q (adjusment) itulah yang akanmenjadi Jadual Induk Produksi untuk periode $\mathrm{t}$. Rumus-rumus diatas diulangi lagi untuk periode-periode berikutnya.

\section{METODOLOGI PENELITIAN}

\section{Jenis Data yang Diperlukan}

Data yang diperlukan untuk analisa meliputi : jenis produksi, proses produksi, waktu produksi, alternatif produksi, jam kerja, mesin, peralatan, jumlah produksi, prosentase cacat, safety stock, serta jumlah permintaan.

\section{Tahapan Pengolahan Data}

1. Peramalan permintaan
\&s Model Trend Linier
so Model Trend Eksponential

2. Uji statistik

3. Perencanaan agregat

\&o Matrik formulasi agregat

so Jadwal rencana agregat

4. Perencanaan disagregat

\&s Matrik formulasi disagregat

so Jadwal Induk Produksi

5. Kalkulasi biaya

\section{HASIL DAN PEMBAHASAN}

Berdasarkan analisa yang telah dilakukan, maka diperoleh hasil sebagai berikut :

\section{Peramalan}

Adapun hasil untuk peramalan 12 periode perencanaan berdasarkan nilai SEE terkecil adalah sebagai berikut :

Tabel 2

Hasil Peramalan untuk 12 periode Mendatang

\begin{tabular}{|c|c|c|c|c|c|c|}
\hline \multirow{2}{*}{ Periode } & \multicolumn{7}{|c|}{ Ramalan permintaan } \\
\cline { 2 - 7 } & TIB & TBU & BMT & BMN & TKG & TKS \\
\hline Jan 2000 & 26181 & 21883 & 19688 & 12194 & 11851 & 7741 \\
\hline Peb 2000 & 27286 & 22995 & 20663 & 12765 & 12454 & 8140 \\
\hline Mar2000 & 28391 & 24106 & 21628 & 13337 & 13057 & 8538 \\
\hline Apr2000 & 29496 & 25218 & 22594 & 13908 & 13661 & 8937 \\
\hline Mei2000 & 30600 & 26330 & 23559 & 14480 & 14264 & 9335 \\
\hline Jun2000 & 31705 & 27441 & 24524 & 15623 & 14867 & 9734 \\
\hline Jul2000 & 32810 & 28553 & 25489 & 16194 & 15471 & 10132 \\
\hline Ags2000 & 33915 & 29664 & 26454 & 16166 & 16074 & 10531 \\
\hline Sept2000 & 35020 & 30776 & 27419 & 16766 & 16677 & 10930 \\
\hline Okt2000 & 36124 & 31887 & 28384 & 17337 & 17281 & 11328 \\
\hline Nop2000 & 37229 & 32999 & 29349 & 17909 & 17884 & 11727 \\
\hline Des2000 & 38334 & 34110 & 30314 & 18480 & 17487 & 12126 \\
\hline Jml & $\mathbf{3 5 7 0 9 1}$ & $\mathbf{3 3 5 9 6 2}$ & $\mathbf{3 0 0 0 7 4 8}$ & $\mathbf{1 8 5 1 5 9}$ & $\mathbf{1 8 1 0 2 8}$ & $\mathbf{1 1 9 2 0 0}$ \\
\hline
\end{tabular}




\section{Penyesuaian peramalan dengan prosenase cacat produk}

Dengan prosentase cacat sebesar $10 \%$, maka didapat hasil sebagai berikut:

Tabel 3

Hasil Ramalan yang Disesuaikan dengan Prosentase Cacat.

\begin{tabular}{|c|c|c|c|c|c|c|}
\hline \multirow{2}{*}{ Periode } & \multicolumn{7}{|c|}{ Ramalan permitaan } \\
\cline { 2 - 7 } & TIB & TBU & BMT & BMN & TKG & TKS \\
\hline Jan 2000 & 29090 & 24315 & 21887 & 13549 & 13168 & 8601 \\
\hline Peb 2000 & 30318 & 25540 & 22959 & 14184 & 13838 & 9044 \\
\hline Mar 2000 & 31546 & 26785 & 24032 & 14819 & 14508 & 9487 \\
\hline Apr 2000 & 32773 & 28020 & 20104 & 15454 & 15179 & 9930 \\
\hline Mei 2000 & 34000 & 29256 & 26176 & 16089 & 15849 & 10373 \\
\hline Jun 2000 & 35228 & 30490 & 27249 & 16724 & 16519 & 10815 \\
\hline Jul 2000 & 35344 & 31726 & 28321 & 17359 & 17190 & 11258 \\
\hline Ags 2000 & 37683 & 32960 & 29393 & 17994 & 17860 & 11701 \\
\hline Sep 2000 & 38911 & 34196 & 30466 & 18629 & 18530 & 12145 \\
\hline Okt 2000 & 40138 & 35430 & 31538 & 19264 & 19200 & 12587 \\
\hline Nop 2000 & 41432 & 36666 & 32610 & 19899 & 19871 & 13030 \\
\hline Des 2000 & 42543 & 37900 & 33683 & 20534 & 20541 & 13473 \\
\hline Jumlah & 429056 & 373294 & 333418 & 204498 & 202253 & 132444 \\
\hline
\end{tabular}

2. Rencana Agregat

Adapun hasil dari Perencanaan Disagregat adalah sebagai berikut :

Tabel 4

Rencana Agregat periode Januari 2000 - Desember 2000

\begin{tabular}{|c|c|c|c|c|c|c|}
\hline \multirow[t]{3}{*}{ Periode } & \multirow[t]{3}{*}{ Permintaan } & \multirow[t]{3}{*}{ Inventory } & \multirow{3}{*}{$\begin{array}{l}\text { ham } \\
\text { kecia }\end{array}$} & \multicolumn{2}{|c|}{ Produksi } & \multirow{3}{*}{$\begin{array}{c}\text { Total } \\
\text { Produksi }\end{array}$} \\
\hline & & & & Reguler & Overtime & \\
\hline & & & & & & \\
\hline 0 & & 14777 & & & & \\
\hline 1 & 184434 & 44305 & 26 & 179657 & & 179657 \\
\hline 2 & 201628 & 44305 & 26 & 157323 & & 157323 \\
\hline 3 & 208823 & 44305 & 26 & 164518 & & 164518 \\
\hline 4 & 206866 & 44305 & 26 & 171711 & & 171711 \\
\hline 5 & 233209 & 44305 & 26 & 178904 & & 178904 \\
\hline 6 & 230402 & 44305 & 25 & 186097 & & 186097 \\
\hline 7 & 236307 & 44305 & 25 & 193200 & & 193200 \\
\hline 8 & 244708 & 44305 & 24 & 185472 & 13813 & 199285 \\
\hline 9 & 251986 & 44305 & 24 & 185472 & 32254 & 217726 \\
\hline 10 & 259175 & 44305 & 26 & 200928 & 13942 & 214870 \\
\hline 11 & 266467 & 44305 & 25 & 193200 & 28942 & 222142 \\
\hline 12 & 275505 & 44305 & 24 & 185472 & 45728 & 231200 \\
\hline
\end{tabular}

Dari hasil yang ada dapat dianalisa bahwa untuk tiap-tiap periode membutuhkan produksi sebesar yang telah tertera pada tabel diatas, dengan jam kerja regular pada periode 1 sampai dengan periode 7 , untuk periode 8 sampai dengan periode12 selain regular time juga memerlukan over time, deman jumlah tenaga kerja sebesar 966 orang.

\section{Perencanaan Disagregat.}

Adapun hasil dari Perencanaan Disagregat adalah sebagai berikut : 
Tabel 5

Jadual Induk Produksi

\begin{tabular}{|l|c|c|c|c|c|c|}
\hline \multirow{2}{*}{ Periode } & \multicolumn{7}{|c|}{ Kode Produksi } \\
\cline { 2 - 7 } & TIB & TBU & BMT & BMN & TKG & TKS \\
\hline Jan 2000 & 34049 & 29467 & 27167 & 16028 & 15658 & 9737 \\
\hline Peb 2000 & 30346 & 25573 & 22979 & 14197 & 13848 & 9053 \\
\hline Mar 2000 & 31588 & 26751 & 24064 & 14839 & 14528 & 9500 \\
\hline Apr 2000 & 32802 & 28045 & 25127 & 15467 & 15192 & 9938 \\
\hline Mei 2000 & 34029 & 29282 & 26199 & 16104 & 15863 & 10383 \\
\hline Jun 2000 & 35259 & 30518 & 27273 & 16739 & 16534 & 10824 \\
\hline Jul 2000 & 35591 & 31953 & 28524 & 17483 & 17314 & 11339 \\
\hline Agt 2000 & 37500 & 32790 & 29242 & 17901 & 17768 & 11641 \\
\hline Sep 2000 & 40829 & 35883 & 31968 & 19547 & 19443 & 12744 \\
\hline Okt 2000 & 40167 & 35464 & 31567 & 19281 & 19219 & 12599 \\
\hline Nop2000 & 41466 & 36701 & 32639 & 19916 & 19890 & 13043 \\
\hline Des 2000 & 42983 & 38258 & 34001 & 20735 & 20735 & 13601 \\
\hline
\end{tabular}

Dari hasil yang tampak pada tabel diatas, dapat dianalisa bahwa untuk jadwal induk produksi yang dihasilkan dari rencana disagregat ini merupakan patokan perusahaan dalam memproduksi barangnya agar tidak terjadi kekurangan ataupun kelebihan produksi.

Tabel 6

Total Inventory Akhir

\begin{tabular}{|l|c|c|c|c|c|c|}
\hline \multirow{2}{*}{ Periode } & \multicolumn{7}{|c|}{ Kode Produksi } \\
\cline { 2 - 7 } & TIB & TBU & BMT & BMN & TKG & TKS \\
\hline Jan 2000 & 2350 & 2200 & 2000 & 1300 & 1500 & 1500 \\
\hline Peb 2000 & 7309 & 7352 & 7280 & 3779 & 3993 & 2636 \\
\hline Mar 2000 & 7337 & 7375 & 7300 & 3792 & 4003 & 2645 \\
\hline Apr 2000 & 7379 & 7411 & 7332 & 3812 & 4023 & 2658 \\
\hline Mei 2000 & 7408 & 7436 & 7355 & 3825 & 4036 & 2666 \\
\hline Jun 2000 & 7437 & 7462 & 7378 & 3840 & 4050 & 2676 \\
\hline Jul 2000 & 7468 & 7490 & 7402 & 3855 & 4065 & 2685 \\
\hline Agt 2000 & 7715 & 7717 & 7605 & 3979 & 4189 & 2766 \\
\hline Sep 2000 & 7532 & 7547 & 7454 & 3886 & 4097 & 2706 \\
\hline Okt 2000 & 9450 & 9234 & 8956 & 4804 & 5010 & 3305 \\
\hline Nop2000 & 9479 & 9268 & 8985 & 4821 & 5029 & 3317 \\
\hline Des 2000 & 9513 & 9303 & 9014 & 4838 & 5048 & 3330 \\
\hline
\end{tabular}

\section{Total Penghematan Biaya}

Tabel 7

Total Penghematan

\begin{tabular}{|c|c|c|c|}
\hline \multirow{2}{*}{$\begin{array}{c}\text { Kode } \\
\text { Produksi }\end{array}$} & \multicolumn{2}{|c|}{ Biaya (Rupiah) } & \multirow{2}{*}{ Penghematan } \\
\cline { 2 - 3 } & Sebelum JIP & Sesudah JIP & \\
\hline TIB & 116102553 & 48968000 & 67137553 \\
\hline TBU & 65662415 & 48593000 & 17069415 \\
\hline BMT & 639312344 & 47696500 & 591615844 \\
\hline BMN & 82934164 & 25135000 & 57799164 \\
\hline TKG & 77108956 & 26389000 & 50719956 \\
\hline TKS & 41660260 & 17424000 & 24236260 \\
\hline Total & $\mathbf{1 0 2 2 7 8 0 6 9 2}$ & $\mathbf{2 1 4 2 0 2 5 0 0}$ & $\mathbf{8 0 8 5 7 8 1 9 2}$ \\
\hline
\end{tabular}

Total Penghematan Biaya setelah menerapkan JIP adalah Rp. 808.578.192 atau setara dengan :

$$
\frac{808578192}{1022780692} \times 100 \%=79,05 \%
$$




\section{KESIMPULAN}

Berdasarkan hasil analisa data maka dapat diambil kesimpulan sebagai berikut :

1. Ramalan permintaan untuk bulan Januari 2000 sampai dengan bulan Desember 2000 adalah sebagai berikut :

Body Timbangan : 38709lunit, Batang ukuran timbangan 335962 unit : Bemper mobil truk : 300065 unit, Bemper mobil niaga : 185159 unit, Tabung kompor gas : 181028 unit, Tabung Klakson : 119200 unit.

2. Jumlah tenaga kerja dengan biaya minimum pada perencanaan produksi periode mendatang sebanyak 966 orang dengan biaya $\mathrm{Rp} 49.431 .714 .000$.

3. Perencanaan agregat dengan menggunakan metode Transportasi memberikan hasil :

\begin{tabular}{|l|l|l|}
\hline No & Bulan & Jumlah \\
\hline 1 & Januari & 179.657 \\
\hline 2 & Februari & 157.323 \\
\hline 3 & Maret & 164.518 \\
\hline 4 & April & 171.711 \\
\hline 5 & Mei & 178.904 \\
\hline 6 & Juni & 186.097 \\
\hline 7 & Juli & 193.200 \\
\hline 8 & Agustus & 199.285 \\
\hline 9 & September & 217.726 \\
\hline 10 & Oktober & 214.870 \\
\hline 11 & Nopember & 222.142 \\
\hline 12 & Desember & 231.200 \\
\hline
\end{tabular}

4. Jadual Induk Produksi untuk 12 periode adalah

\begin{tabular}{|l|c|c|c|c|c|c|}
\hline \multirow{2}{*}{ Periode } & \multicolumn{7}{|c|}{ Kode Produksi } \\
\cline { 2 - 7 } & TIB & TBU & BMT & BMN & TKG & TKS \\
\hline Jan 2000 & 34049 & 29467 & 27167 & 16028 & 15658 & 9737 \\
\hline Peb 2000 & 30346 & 25573 & 22979 & 14197 & 13848 & 9053 \\
\hline Mar 2000 & 31588 & 26751 & 24064 & 14839 & 14528 & 9500 \\
\hline Apr 2000 & 32802 & 28045 & 25127 & 15467 & 15192 & 9938 \\
\hline Mei 2000 & 34029 & 29282 & 26199 & 16104 & 15863 & 10383 \\
\hline Jun 2000 & 35259 & 30518 & 27273 & 16739 & 16534 & 10824 \\
\hline Jul 2000 & 35591 & 31953 & 28524 & 17483 & 17314 & 11339 \\
\hline Agt 2000 & 37500 & 32790 & 29242 & 17901 & 17768 & 11641 \\
\hline Sep 2000 & 40829 & 35883 & 31968 & 19547 & 19443 & 12744 \\
\hline Okt 2000 & 40167 & 35464 & 31567 & 19281 & 19219 & 12599 \\
\hline Nop2000 & 41466 & 36701 & 32639 & 19916 & 19890 & 13043 \\
\hline Des 2000 & 42983 & 38258 & 34001 & 20735 & 20735 & 13601 \\
\hline
\end{tabular}

5. Setelah dilaksanakan Perencanaan dengan JIP didapatkan total penghematan biaya sebesar Rp 5.829.363.807 atau setara dengan $76.3 \%$. 


\section{DAFTAR PUSTAKA}

Nasution, Arman Hakim, Perencanaan dan

Pengendalian Persediaan, Fakultas Teknik Industri, ITS.

Elsayed, Elsayed A, and Thomas $\mathrm{O}$ Boucher, 1985, Analisys And Control

Of Production System, New Jersey;

Pratice- Hall, Inc.

Bedworth, david D dan Bailey, James C,

Integrated Production Control System, John Wiley dan Sons, New York.
Biegel Jhon E, 1992, Pengendalian Produksi Suatu Pendekatan Kuantitatif, Akademika Pressindo, Jakarta.

Nahmias Steven, 1997, Production And Operation Analysis, MC Graw- Hill International Edition, Singapura.

SU, Awat, J Napa,Drs, Metode peramalan Kuantitatif, Liberty ,Yogyakarta,

Dervitsiotis, Kostas N, 1990, Operations Management, New York, MC GrawHill Book Co, 1981. 